\title{
Intracerebellar Microinjection of an H4 Agonist Impairs Memory Consolidation in Open Field and Rotarod Tasks in Mice
}

\author{
C.E.M. Fernandes ${ }^{*}$, E.M. Guilherme ${ }^{\#}$, K.R. Serafim, A.C.L. Gianlorenço and R. Mattioli \\ Laboratory of Neuroscience, Physiotherapy Department, Center of Biological Sciences and Health, Federal \\ University of Sao Carlos, Brazil \\ \#: These authors contributed equally to this work
}

*Corresponding author: Carlos Eduardo Monici Fernandes, Laboratory of Neuroscience, Physiotherapy Department, Center of Biological Sciences and Health, Federal University of Sao Carlos, Rodovia Washington Luiz, 235. Bairro Monjolinho, CEP: 13565-905, São Carlos, SP, Brazil, Tel: +55-16 3351-8628

\begin{abstract}
The cerebellum is known to participate in motor functions, but the role of the histaminergic system, and specifically the $\mathrm{H} 4$ receptors, in its functions is still unclear. In the present study, we investigated the effects of intravermis microinjections of an $\mathrm{H} 4$ receptor agonist (VUF-8430) on mice behavior undergoing a rotarod (Experiment 1) and open field (Experiment 2) test. The cerebellar vermis of male mice was implanted with a single guide cannula. All experiments were performed on two consecutive days: exposure (R1- first day in the rotarod test or OF1- first day in the open field test), followed by re-exposure (R2- second day in the rotarod test or OF2- second day in the open field test) $24 \mathrm{~h}$ later. The animals received saline $(\mathrm{SAL})$ or VUF $(0.15 \mathrm{nmol}$; $0.49 \mathrm{nmol} ; 1.48 \mathrm{nmol} / 0.1 \mu \mathrm{l})$ administered intravermis immediately after R1 or OF1. The data were analyzed using one-way ANOVA and Duncan's post hoc test. In Experiment 1 , the drug led to a decrease of consolidation latency for the VUF 0.49 and VUF 1.48 groups compared to the control SAL group in R2. In Experiment 2, the VUF 1.48 group had a significant increase in freezing time in the open field in OF2 compared to OF1. These results suggests that the $\mathrm{H} 4$ agonist VUF 8430 at its highest dose $(1.48 \mathrm{nmol}) \mathrm{im}-$ pairs memory consolidation in open field and rotarod tasks in mice (Graphical abstract).
\end{abstract}

\section{Keywords}

Cerebellum, Histaminergic system, H4 receptors, Memory consolidation, Learning, Mice

\section{Introduction}

The cerebellum has a role in regulating movement planning, accessing and sorting sensorial information to perform a specific action, and in motor learning [1]. Studies have shown that it also participates in nonmotor functions, such as cognitive and emotional processes [2,3]. Popa, et al. [4] proposed that the cerebellum's role in motor and non-motor functions is related to a common way of information processing, suggesting that the cerebellar cortex has the capacity to establish connections between different sensorial signals.

The cerebellum also participates in the perception and recognition of emotional information, as well as in the experience and regulation of emotional states related to motor, cognitive and social behaviors, emotional memory, pain, language and mood disorders [5]. Sacchetti, et al. [6] suggested an involvement of the cerebellum - more specifically the cerebellar vermis in conditioned fear, demonstrating its role in aversive memory consolidation, inhibiting or facilitating motor activity through freezing or active avoidance behaviors.

The histaminergic system actively participates in cerebellum-mediated motor balance, coordination and emotional functions $[7,8]$ and four types of receptors mediate the actions of the biological effects of histamine, including $\mathrm{H} 1, \mathrm{H} 2, \mathrm{H} 3$ and $\mathrm{H} 4$ receptors $[9,10]$. The 


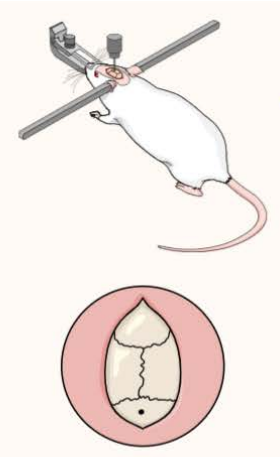

Cerebellar vermis: $6.5 \mathrm{~mm}$ posterior to the Bregma, $0.0 \mathrm{~mm}$ lateral to the midline; $2.0 \mathrm{~mm}$ ventral to the skull surface
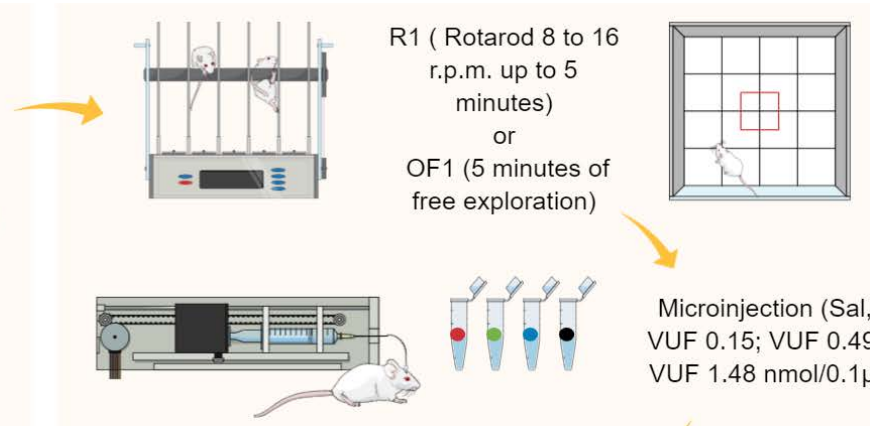

Microinjection (Sal, VUF 0.15; VUF 0.49; VUF $1.48 \mathrm{nmol} / 0.1 \mu \mathrm{l}$

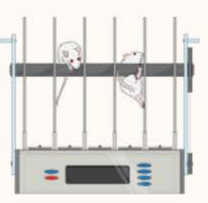

R2 ( Rotarod 8 to 16 r.p.m. up to 5 minutes) or

OF2 (5 minutes of free exploration)

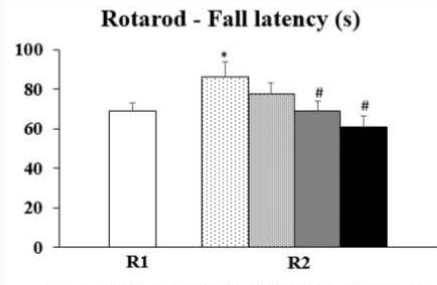

$\square$ Pool $\square$ SAL $\square$ VUF $0.15 \quad$ घVUF $0.49 \quad$-VUF 1.48

Open Field - Freezing (s)

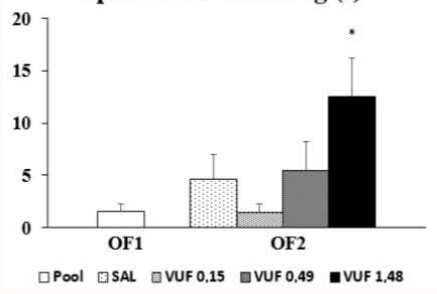

$\mathrm{H} 4$ receptors are expressed in hematopoietic cells, acting on allergic and inflammatory processes [11]. However, recent studies using RNA messenger detection in the cerebellum, amygdala, corpus callosum, prefrontal cortex and thalamus, have reported a participation of these receptors in the central nervous system (CNS) both in humans [9] and mice [12]. A study by Sanna, et al. [13] was the first to describe the behavioural phenotype of $\mathrm{H} 4$ receptors-deficient mice and the results illustrated that these receptors modulates various neurophysiological functions such as locomotor activity and anxiety, confirming the importance of the integrity and functionality of these receptors in the histaminergic regulation of neuronal functions.

The drug VUF 8430 has a high affinity for $\mathrm{H} 4$ receptors and can be used as an important pharmacological tool in research [14]. In our laboratory, we demonstrated that VUF 8430 impaired emotional memory consolidation in mice via the cerebellar vermis, regardless of whether the proposed activities were related to anxiety, as in the elevated plus maze, or related to fear, as in an inhibitory avoidance task [15]. Furthermore, a decrease in protein expression in the cerebellar vermis was verified by CREB and phosphorylated CREB levels, which corroborates these deficits [16].

There are few studies of $\mathrm{H} 4$ receptors in the CNS, and our group was the first to investigate them in the cerebellum through different behavioral tests $[15,17]$ to elucidate the neuronal processes modulated by $\mathrm{H} 4$ receptors. Thus, the aim of the present study was to advance the understanding of functions of $\mathrm{H} 4$ receptors in the cerebellar vermis and its relationship on emotional memory consolidation and motor activity in mice exposed and re-exposed to rotarod and open field tests.

\section{Methods}

\section{Animals}

The experimental subjects were 86 adult male Swiss mice (Federal University of São Carlos - UFSCar, SP, Brazil), weighing $25-35 \mathrm{~g}$, and maintained under a $12 \mathrm{~h}$ light cycle (lights on at 7:00 a.m.) in a controlled environment at a temperature of $23 \pm 1^{\circ} \mathrm{C}$ and humidity of $50 \pm 5 \%$. All mice were naïve to behavioral tests at the beginning of the study. The experimental sessions were conducted during the light period of the cycle $(8: 00-12: 00 \mathrm{~h})$ to minimize the influence of the circadian rhythm on behavioral responses.

All procedures were approved by the Animal Ethics Commission of the Federal University of Sao Carlos (protocol 8336250515), which follows the standards of the Brazilian Neuroscience and Behavior Society (SBNeC), which are based on the US National Institutes of Health Guide for Care and Use of Laboratory Animals.

\section{Drug}

VUF 8430 (Sigma Chemical Co., St. Louis, MO, USA), an $\mathrm{H} 4$ receptor agonist, was dissolved in sterile $0.9 \%$ saline solution (SAL). The VUF solution was microinjected at doses of $0.15,0.49$ and $1.48 \mathrm{nmol}$ in a volume of 0.1 $\mu \mathrm{l}$. The doses were selected based on a previous study conducted by Fernandes, et al. [15]. The solutions were stored in coded tubes.

\section{Surgery and microinjection}

Mice received a general anesthesia with ketamine hydrochloride $(100 \mathrm{mg} / \mathrm{kg}, \mathrm{IP})$ and xylazine $(10 \mathrm{mg} /$ $\mathrm{kg}, \mathrm{IP}$ ) and were then treated with local anesthesia on the scalp (3\% lidocaine with norepinephrine; 1:50.000) and placed in a stereotaxic instrument. The cerebellar vermis of the mice was implanted with a single 7-mm guide cannula (25-gauge), according to the following coordinates from the mouse brain atlas of Franklin and Paxinos [18]: $6.5 \mathrm{~mm}$ posterior to the Bregma; $0 \mathrm{~mm}$ lateral to the midline; and $2.0 \mathrm{~mm}$ ventral to the skull surface. The guide cannula was fixed to the skull using dental acrylic and jeweler's screws. A dummy cannula (33-gauge) was inserted into the guide cannula to re- 
duce the incidence of occlusion. Postoperative analgesia was provided for 3 days by adding acetaminophen $(200 \mathrm{mg} / \mathrm{ml})$ to the drinking water at a ratio of $0.2 \mathrm{ml}$ acetaminophen to $250 \mathrm{ml}$ water for a final concentration of $0.16 \mathrm{mg} / \mathrm{ml}$.

After four days of recovery from the surgery, saline or drug solutions were infused into the cerebellar vermis using a microinjection unit (33-gauge cannula; Insight Equipamentos Científicos Ltda, Brazil), which was attached to a $5 \mu \mathrm{l}$ Hamilton micro syringe via polyethylene tubing, and an infusion pump that was programmed to deliver a volume of $0.1 \mu \mathrm{l}$ over $60 \mathrm{~s}$.

\section{Apparatus and experimental procedures}

Rotarod: The automated rotarod apparatus consists of an acrylic box $(450 \times 540 \times 350 \mathrm{~mm})$ with an $8 \mathrm{~cm}$ diameter cylinder, transversely installed approximately $20 \mathrm{~cm}$ from the floor of the equipment, kept rotating through a motor. The box is divided into five bays, approximately $3 \mathrm{~cm}$ wide, allowing the analysis of five animals simultaneously. A sensor located on the floor of the device measures the falling latency of the animals automatically.

The rotarod test was performed on two consecutive days ( $R 1$ and R2). The mice walked over a rotating cylinder to avoid falling. On day one (R1), the animals were initially kept on the rotarod for 5 minutes, allowing habituation to the apparatus. Fifteen minutes after habituation, the mice were exposed to the rotarod at an accelerating speed (8 to 16 r.p.m.) until they fell or up to 5 minutes [19] to assess motor coordination and motor learning. The accelerated rotarod test was performed to evaluate motor coordination and motor learning by measuring latency to falling off a rod that was rotated with increasing velocity [20]. After the end of R1, the animals received the pharmacological treatment. On R2, the animals were re-exposed at the same experimental conditions as R1, without the microinjections, to characterize motor learning. The increase or decrease of the fall latency were indicative of improvement or reduction on motor learning, respectively. The apparatus was cleaned with $5 \%$ ethanol between each animal.

Open field: The open field apparatus consisted of a wood box $(52.5 \mathrm{~cm} \times 52.5 \mathrm{~cm})$ with lateral walls $(27.5$ $\mathrm{cm})$, and a base divided in 25 quadrants. This test allows the simultaneous evaluation of motor and anxiety-like behaviors [21].

The open field test was performed on two consecutive days (OF1 and OF2), on which the animal was carefully placed at the center of the open field, and free exploration was allowed for 5 minutes. After the end of OF1, the animals received the pharmacological treatment according to the microinjection procedure previously described.

The motor and exploratory behaviors were assessed by recording the number of crossed quadrants and rearings, respectively. The non-motor behavior was evaluated measuring the time spent in a central area from the apparatus, and the time of freezing during the test. The difference between OF1 and OF2 were indicative of the modulation of learning consolidation [22]. At the end of each session, the floor and walls of the apparatus were cleaned with $5 \%$ ethanol.

\section{Histological analysis}

At the end of testing, the animals received an anesthetic overdose, followed by a $0.1 \mu$ infusion of $1 \%$ methylene blue according to the microinjection procedure. The injection sites were verified histologically according to the atlas of Franklin and Paxinos [18]. Animals with injection sites outside the cerebellar vermis were excluded from the study. Histological analysis confirmed that a total of 86 mice exhibited accurate positioning of the cannula placements in the cerebellar dorsal vermis, particularly at coordinates 6.24 and 6:36. The sample sizes of the different experiments cohorts were as follows:

Experiment 1: SAL $(n=10)$, VUF $0.15 \mathrm{nmol}(\mathrm{n}=11)$, VUF $0.49 \mathrm{nmol}(\mathrm{n}=12)$ and VUF $1.48 \mathrm{nmol}(\mathrm{n}=11)$; Experiment 2: SAL $(n=10)$, VUF $0.15 \mathrm{nmol}(n=10)$, VUF $0.49 \mathrm{nmol}(\mathrm{n}=11)$ and VUF $1.48 \mathrm{nmol}(\mathrm{n}=11)$.

\section{Statistical analysis}

All data passed the tests of normality and variability, and all the results were analyzed using Levene's tests for homogeneity of variance. The data were analyzed using a one-way ANOVA. Differences indicated by significant $F$ values were further verified by post hoc Duncan's multiple range tests. In all cases, $p<0.05$ was considered significant.

\section{Results}

\section{Experiment 1}

Effects of intravermis cerebellar microinjections of SAL or VUF-8430 $(0.15 \mathrm{nmol}, 0.49 \mathrm{nmol}$ or $1.48 \mathrm{nmol})$ on motor learning consolidation in mice exposed (R1) and re-exposed (R2) to a rotarod test.

Forty-four animals had an accurate cannula placement and were included in Experiment 1. The one-way ANOVA indicated that were no significant differences between the animals before the microinjections, which allowed the use of R1 as a pool.

The statistical analysis revealed a difference between the testing days (R1 and R2) $[F(3,40)=3.51, p<0.01]$ and Duncan's test indicated a significant increase in the consolidation latency compared to R1 results (pool) for animals that received saline (SAL). Moreover, a significant difference was detected between the groups on R2 $(p<0.01)$, and the post hoc analysis indicated a decrease in consolidation latency for the VUF 0.49 and VUF 1.48 groups compared to the control group that re- 


\section{Rotarod - Fall latency (s)}

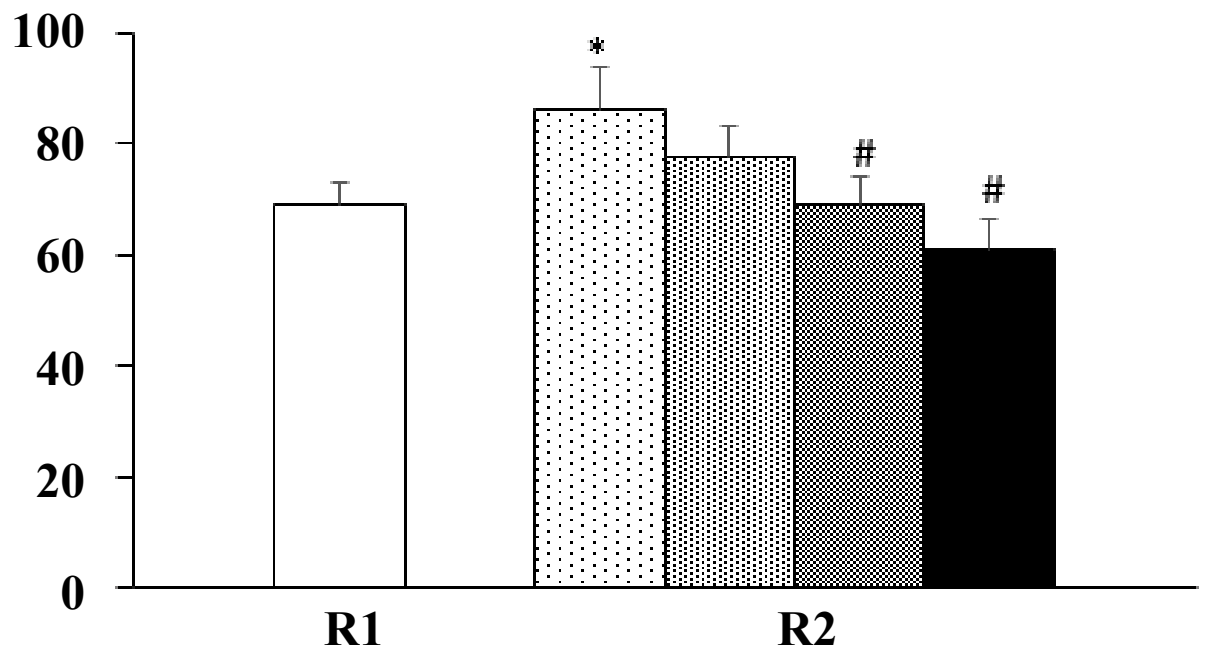

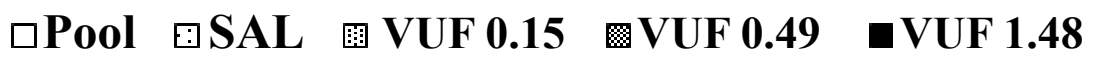

Figure 1: Effects of intravermis cerebellar microinjections of SAL or VUF-8430 ( $0.15 \mathrm{nmol}, 0.49 \mathrm{nmol}, 1.48 \mathrm{nmol})$ on memory consolidation of motor learning on rotarod. Mean \pm SEM for the fall latency [seconds (s)]. Groups: SAL ( $n=10)$, VUF 0.15 $\mathrm{nmol}(\mathrm{n}=11)$, VUF $0.49 \mathrm{nmol}(\mathrm{n}=12)$ and VUF $1.48 \mathrm{nmol}(\mathrm{n}=11) .{ }^{*} \mathrm{p}<0.05$ compared to R1 (pool); ${ }^{p}<0.05$ compared to R2 control group (SAL). One-way ANOVA and Duncan's post hoc test were used for statistical analyses.

\section{Open Field - Freezing (s)}

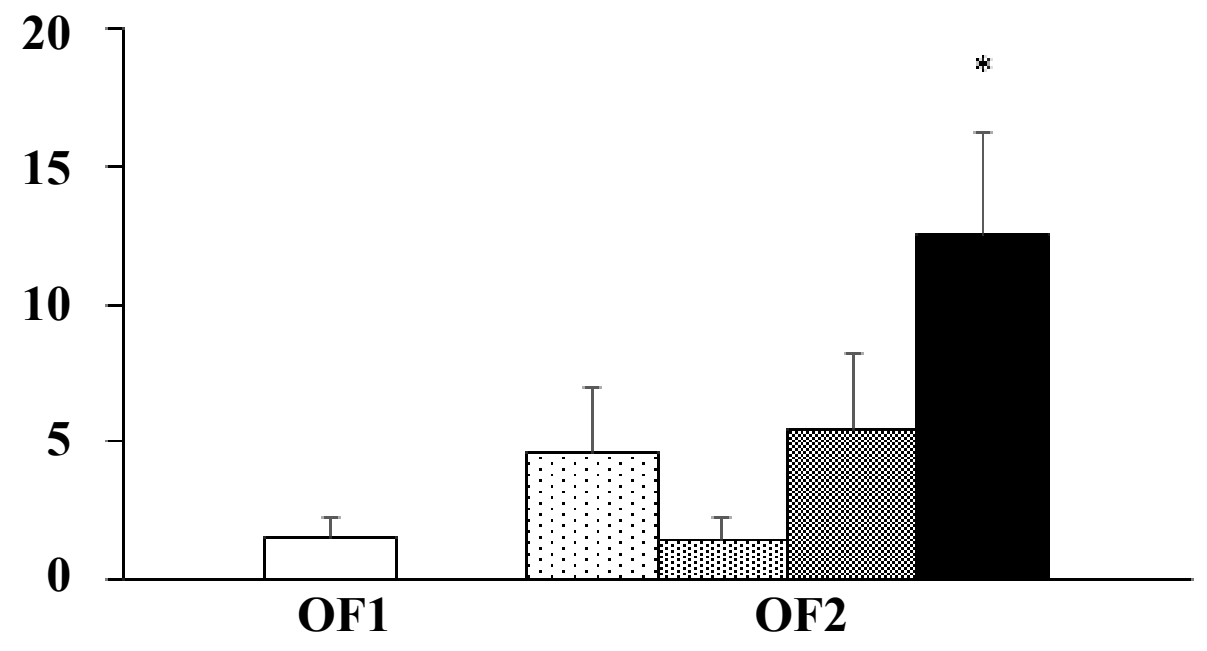

\section{Pool $\boxminus$ SAL 圈 VUF 0.15}

Figure 2: Effects of intravermis cerebellar microinjections of SAL or VUF-8430 ( $0.15 \mathrm{nmol}, 0.49 \mathrm{nmol}, 1.48 \mathrm{nmol})$ on the open field test. Mean \pm SEM for the time of freezing in seconds (s). Groups: SAL $(n=10)$, VUF $0.15 \mathrm{nmol}(\mathrm{n}=10)$, VUF $0.49 \mathrm{nmol}$ $(n=11)$ and VUF $1.48 \mathrm{nmol}(n=11)$. ${ }^{p}<0.05$ compared to OF1 (pool). One-way ANOVA and Duncan's post hoc test were used for statistical analyses.

ceived SAL (Figure 1).

\section{Experiment 2}

Effects of intravermis cerebellar microinjections of SAL or VUF-8430 (0.15 nmol, $0.49 \mathrm{nmol}$ or $1.48 \mathrm{nmol})$ on learning consolidation in mice exposed (OF1) and reexposed (OF2) to an open field test.
Forty-two animals had an accurate cannula placement and were included in Experiment 2. The one-way ANOVA indicated that were no significant differences between the animals before the microinjections, which allowed the use of OF1 as a pool.

Statistical analysis showed a difference between testing days (OF1 and OF2) for the time that the mice 
spent frozen at the open field $\left[\mathrm{F}_{(3,38)}=2.94, \mathrm{p}<0.05\right]$. Duncan's post hoc analysis revealed that the group that received the higher dose of VUF-8430 (1.48 $\mathrm{nmol}$ ) had a significant increase in immobility time in the open field compared to OF1 results (pool; $p<0.05$; Figure 2). A one-way ANOVA indicated that there was no difference between the groups (OF1 and OF2; Table 1) in the number of crossed quadrants $\left[F_{(3,38)}=0.47, p>0.05\right]$, number of rearings $\left.\left[F_{(3,38)}=0.84, p>0.05\right)\right]$ or time in the central area $\left[F_{(3,38)}=1.26, p>0.05\right]$.

\section{Discussion}

The results of Experiment 1 demonstrated that the microinjections in the cerebellar vermis of the histaminergic $\mathrm{H} 4$ receptor agonist VUF 8430 at the doses of 0.49 $\mathrm{nmol}$ and $1.48 \mathrm{nmol}$ decreased the latency of the animals undergoing the rotarod test, indicating that these doses impaired the consolidation of motor learning in mice.

Classically, the cerebellum participates in the necessary plastic changes for motor learning, and cerebellar ablation results in an inability to acquire certain adaptive behavior [23]. The cerebellum has a network of regulatory pathways for correct control of a given motor act, comparing, modulating and adjusting the stimuli through its projections to cortical motor areas, contributing to the regulation and planning of movement as well as sensory acquisition and temporal organization [24]. Therefore, individuals with cerebellar injuries present disturbances in the precision and coordination of the movements performed [1]. In the present study, we believe that the deficits found in the rotarod test after the drug microinjection into the cerebellar vermis might be related to the animals' motor coordination since we did not observe deficits in mobility in the EPM [15].

Song, et al. [25] using the rotarod test, observed that the microinjection of histamine $(\mathrm{HA})$ in the cerebellar interpositus nucleus in rats improves motor performance, balance and coordination abilities, suggesting that hypothalamic-cerebellar histaminergic projections can modulate the cerebellar circuit to ensure the accuracy of movements. In addition, HA excites neurons from the dentate nucleus in the cerebellum via $\mathrm{H} 2$ receptors, suggesting the involvement of these projections in the planning and initiating of movement [26]. In the present study, when we used an $\mathrm{H} 4$ agonist microinjected in the cerebellar vermis in mice, there was a deficit in the consolidation of motor learning in the animals in the rotarod test. Coffman, et al. [27] suggested that there is a site in the cerebellar vermis where the cortical motor areas can influence the descending control systems involved in the regulation of whole-body posture and locomotion and this could explain the different results obtained in other cerebellum regions.

As observed, the histaminergic neural system is involved in the regulation of locomotor activity. However, studies investigating the effects of HA on rodent motor control have different results. While some studies have shown that HA produces a biphasic effect on spontaneous locomotor activity in rats, with initial transient hypoactivity followed by hyperactivity, and that the reduction of HA in knockout animals to histaminergic receptors causes a decrease in locomotor activity, demonstrating a facilitating role of this neurotransmitter in motor activity $[28,29]$; other studies involving i.c.v. HA microinjections observed only the hypoactivity $[30,31]$. Galeotti, et al. [19] suggest a significant deficit in the involvement of motor coordination in mice undergoing the rotarod test when the highest dose of the $\mathrm{H} 4$ agonist VUF 8430 was used, corroborating the results obtained in the present study.

In Experiment 2, the intravermis microinjections of VUF 8430 did not result in significant differences in locomotor and exploratory activity during re-exposure to the open field, or on the amount of time spent on the central and peripheral areas of the apparatus. However, the $1.48 \mathrm{nmol}$ dose significantly increased the immobility time of the animals re-exposed to the open field (OF2) when compared to the first day of testing (OF1). These data may indicate an impairment via cerebellar $\mathrm{H} 4$ receptors in the memory consolidation on re-exposure to the apparatus.

Escaping, fighting or freezing behaviors are responses classically related to aversive stimuli [32], and the determination of the defensive mode is dependent on different factors, such as the physical and temporal proximity of the threat and familiarity with absence or pres-

Table 1: Effects of intravermis cerebellar microinjections of VUF-8430 in mice exposed (OF1) and re-exposed (OF2) to the open field test.

\begin{tabular}{|l|l|l|l|l|l|}
\hline \multirow{2}{*}{ Behaviour } & \multicolumn{1}{|c|}{ OF1 } & \multicolumn{3}{c|}{ OF2 } \\
\cline { 2 - 6 } & Pool & SAL & VUF 0.15 nmol & VUF 0.49 nmol & VUF 1.48 nmol \\
\hline Crossed quadrants & $185.83 \pm 12.67$ & $190.20 \pm 30.41$ & $150.80 \pm 19.44$ & $188.18 \pm 31.24$ & $163.27 \pm 31.40$ \\
\hline Number of readings & $30.33 \pm 2.92$ & $39.90 \pm 7.94$ & $29.40 \pm 6.65$ & $26.55 \pm 5.44$ & $25.82 \pm 5.38$ \\
\hline Time in the central area & $31.74 \pm 3.41$ & $27.20 \pm 6.91$ & $34.20 \pm 8.20$ & $22.48 \pm 5.00$ & $18.96 \pm 3.12$ \\
\hline Time of freezing & $1.56 \pm 0.77$ & $4.60 \pm 2.39$ & $1.48 \pm 0.82$ & $5.47 \pm 2.71$ & $12.50 \pm 3.71^{*}$ \\
\hline
\end{tabular}

The data are presented as the mean values ( \pm SEM). The number of crossed quadrants, number of rearings, time spent in the central area and time of freezing were measured at OF1 and OF2. One- way ANOVA did not show significant differences among groups at OF1, which allowed the use of OF1 as a pool. *: Significant difference between test days (OF1 and OF2) p < 0.05. 
ence of an escape route [33]. According to Fanselow [34], an animal may attempt to flee in the presence of an escape route, to fight in face of imminent danger, or to remain immobile if none of these environmental stimuli is available.

Immobility behavior is defined as the complete absence of movements, except for the movements required for respiration [35], and may occur in the laboratory context in situations in which the animal is re-exposed to experiences previously related to an aversive stimuli $[36,37]$. Although the open field is a behavioral model classically used in the investigation of locomotor and exploratory behavior; agoraphobia, separation of the animal from its social group and forced confrontation with an unknown environment, triggered by exposure to this environment can be considered a stressor stimulus to rodents [21].

In a previous study conducted in our laboratory, animals exposed to the open field in a single exposure after administration of VUF 8430 showed a significant increase in the number of crosses, rearings and time spent in the central area of the apparatus compared to control, suggesting modulation by this drug on locomotor and exploratory behaviors [17]. Such an increase in the exploratory component may be interpreted as a search for an escape route during a first exposure to the stressor represented by the apparatus. In the present study, we hypothesized that the VUF 8430 acts to intensify the aversive component represented by the open field once explored, which explains the defensive behavior represented by the increase of freezing time. These findings are in agreement with the study by Fernandes, et al. [15] that demonstrated the effects of this drug in the modulation of aversive memory consolidation in mice undergoing anxiety and fear behavioral tests, which impaired performance in both models.

As known, VUF-8430 also has an affinity to the H3 receptors as an agonist [14], but we believe that the effect was, at least in part, due to the $\mathrm{H} 4$ receptors. We achieved this conclusion based on the comparison of different results obtained from previous studies involving the $\mathrm{H} 3$ receptors. A study by Nuutinen, et al. [38] showed that an $\mathrm{H} 3$ agonist injected intraperitoneally did not alter the performance on the rotarod, while in the present study, an $\mathrm{H} 4$ agonist at the highest dose microinjected into the cerebellar vermis impaired motor learning in this apparatus. Likewise, the i.p. injection of the $\mathrm{H} 3$ antagonist E177 after habituation did not altered motor and anxiety-like behaviors of male rats submitted to the open field test [39]. The absence of effects of $\mathrm{H} 3$ receptors antagonists in the open field test was also observed after intracerebellar [17] and intra basolateral amygdala administrations [40], therefore indicating a putative $\mathrm{H} 4$ effect in this study.

As the central expression of the $\mathrm{H} 4$ receptors has only recently been discovered, a limited amount of studies is available in the literature. Thus, there is a need for further evidence to assist in guiding future investigations, elucidating the role of these receptors in the CNS, and making them potential therapeutic targets for diverse clinical manifestations, such as amnestic disorders, since in both models used in the present study, the VUF 8430 at its highest dose $(1.48 \mathrm{nmol})$, impaired learning. Hence, we suggest that the histaminergic neural system, via $\mathrm{H} 4$ receptors present in the cerebellar vermis, can modulate motor learning and emotional memory consolidation in mice, leading to behavioral adjustments as observed in this study.

\section{Acknowledgments}

The authors are grateful for the financial support provided by FAPESP (grants \#2015/15342-0 and \#2015/22309-9), CNPq (grant \#302011/2018-8), and CAPES (Finance Code 001).

\section{References}

1. Manto M, Bower JM, Conforto AB, Delgado-García JM, Farias da Guarda SN, et al. (2012) Consensus Paper: Roles of the cerebellum in motor control - the diversity of ideas on cerebellar involvement in movement. Cerebellum 11: 457487.

2. Schmahmann JD (2019) The cerebellum and cognition. Neuroscie Lett 688: 62-75.

3. Koziol LF, Budding D, Andreasen N, D'Arrigo S, Bulgheroni S, et al. (2014) Consensus Paper: The cerebellum's role in Movement and Cognition. Cerebellum 13: 151-177.

4. Popa LS, Hewitt AL, Ebner TJ (2014) The cerebellum for jocks and nerds alike. Front Sys Neuroscie 8: 113.

5. Adamaszek M, D'Agata F, Ferrucci R, Habas C, Keulen S, et al. (2017) Consensus Paper: Cerebellum and Emotion. Cerebellum 16: 552-576.

6. Sacchetti B, Scelfo B, Strata P (2009) Cerebellum and emotional behavior. Neuroscience 162: 756-762.

7. Gianlorenço ACL, Riboldi AM, Silva-Marques $B$, Mattioli $R$ (2015) Cerebellar vermis $\mathrm{H} 2$ receptors mediate fear memory consolidation in mice. Neuroscie Lett 587: 57-61.

8. Li B, Zhu JN, Wang JJ (2014) Histaminergic afferent system in the cerebellum: structure and function. Cerebellum Ataxias 1: 5 .

9. Strakhova MI, Nikkel AL, Manelli AM, Hsieh GC, Esbenshade TA, et al. (2009) Localization of histamine $\mathrm{H} 4$ receptors in the central nervous system of human and rat. Brain Res 1250: 41-48.

10. Haas H, Panula P (2003) The Role of Histamine and the tuberomamillary nucleus in the nervous system. Nat Rev Neurosci 4: 121-130.

11. Haas HL, Sergeeva OA, Selbach O (2008) Histamine in the nervous system. Physiol Rev 88: 1183-1241.

12. Connelly WM, Shenton FC, Lethbridge N, Leurs R, Waldvogel HJ, et al. (2009) The histamine $\mathrm{H} 4$ receptor is functionally expressed on neurons in the mammalian $\mathrm{CNS}$. $\mathrm{Br} \mathrm{J}$ Pharmacol 157: 55-63.

13. Sanna MD, Ghelardini C, Thurmond RL, Masini E, Galeotti N (2017) Behavioural phenotype of Histamine $\mathrm{H} 4$ receptor knockout mice: Focus on central neuronal functions. Neuropharmacology 114: 48-57. 
14. Lim HD, Adami M, Guaita E, Werfel T, Smits RA, et al (2009) Pharmacological characterization of the new histamine $\mathrm{H} 4$ receptor agonist VUF 8430 . Br J Pharmacol 157: 34-43.

15. Fernandes CEM, Serafim KR, Gianlorenco ACL, Mattiol $\mathrm{R}$ (2017) Intra-vermis H4 agonist impairs performance in anxiety - and fear - mediated models. Brain Res Bull 135: 179-184.

16. Fernandes CEM, Serafim KR, Gianlorenço ACL, Mattioli $R$ (2019) Systemic injection of an $\mathrm{H} 4$ receptor agonist induces a decrease in CREB and pCREB levels in the cerebellar vermis and prefrontal cortex in mice. Braz $\mathrm{J}$ Med Biol Res 52: e8334.

17. Guilherme EM, Silva-Marques B, Fernandes CEM, Russo TL, Mattioli R, et al. (2018) Intracerebellar microinjections of histaminergic compounds on locomotor and exploratory behaviors in mice. Neuroscie Lett 687: 10-15.

18. Franklin KBJ, Paxinos G (2001) The Mouse Brain in Stereotaxic Coordinates. ( $2^{\text {nd }}$ edn), Elsevier, Science, California.

19. Galeotti N, Sanna MD, Ghelardini C (2013) Pleiotropic effect of histamine $\mathrm{H} 4$ receptor modulation in the central nervous system. Neuropharmacol 71: 141-147.

20. Hirata H, Takahashi A,Shimoda Y, Koide T (2016) Caspr3-Deficient mice exhibit low motor learning during the early phase of the accelerated rotarod task. Plos One 11 : e0147887.

21. Prut L, Belzung C (2003) The open field as a paradigm to measure the effects of drugs on anxiety- like behaviors: A review. Eur J Pharmacol 463: 3-33.

22. Popović N, Giménez de Béjar V, Caballero-Bleda M, Popović M (2017) Verapamil Parameter- and Dose-Dependently impairs memory consolidation in open field habituation task in rats. Front Pharmacol 7.

23. Bloedel JR, Bracha V, Kelly TM, Wu JZ (1991) Substrates for motor learning: Does the cerebellum do it all? Ann NY Acad Scie 627: 305-318.

24. Nixon PD, Passinghan RE (2001) Predicting sensory events - the role of the cerebellum in motor learning. Exp Brain Res 138: 251-257.

25. Song YN, Li H-Z, Zhu J-N, Guo C-L, Wang J-J (2006) Histamine improves rat rotarod and balance beam performances through $\mathrm{H} 2$ receptors in the cerebellar interpositus nucleus. Neuroscience 140: 33-43.

26. Qin YT, Ma SH, Zhuang QX, Qiu YH, Li B, et al. (2011) Histamine evokes excitatory response of neurons in the cerebellar dentate nucleus via $\mathrm{H} 2$ receptors. Neuroscie Lett 502: 133-137.

27. Coffman KA, Dum RP, Strick PL (2011) Cerebellar vermis is a target of projections from the motor areas in the cerebral cortex. PNAS 108: 16068-16073.
28. Bristow LJ, Bennett GW (1988) Biphasic effects of intra-accumbens histamine administration on spontaneous motor activity in the rat: $\mathrm{A}$ role for central histamine receptors. $\mathrm{Br}$ J Pharmacol 95: 1292-1302.

29. Chiavegatto S, Nasello AG, Bernardi MM (1998) Histamine and spontaneous motor activity: biphasic changes, receptors involved and participation of the striatal dopamine system. Life Scie 62: 1875-1888.

30. Inoue I, Yanai K, Kitamura D, Taniuchi I, Kobayashi T, et al. (1996) Impaired locomotor activity and exploratory behavior in mice lacking histamine $\mathrm{H} 1$ receptors. PNAS 93: 13316-13320.

31. Toyota H, Dugovic C, Koehl M, Laposky AD, Weber C, et al. (2002) Behavioral characterization of mice lacking histamine H3 receptors. Mol Pharmacol 62: 389-397.

32. Blanchard DC, Blanchard RJ (1988) Ethoexperimental approaches to the biology of emotion. Ann Rev Psychol 39: 43- 68.

33. Fanselow M, Lester LS (1988) A functional behavioristic approach to aversively motivated behavior: Predatory imminence as a determinant of topography of defensive behavior. Evol Learn 185-211.

34. Fanselow MS (1994) Neural organization of the defensive behavior system responsible for fear. Psychon Bull Rev 1: 429-438.

35. Bolles RC, Riley AL (1973) Freezing as an avoidance response: another look at the operant- respondent distinction. Learn Motiv 4: 268-275.

36. Kozlowska K, Walker P, McLean L, Carrive P (2015) Fear and the Defense Cascade: Clinical implications and manegement. Harv Rev Psychiatry 23: 263-287.

37. Arakawa H, Iguchi $Y(2018)$ Ethological and multi-behavioral analysis of learning and memory performance in laboratory rodent models. Neuroscie Res 135: 1-12.

38. Nuutinen S, Vanhanen J, Pigni MC, Panula P (2011) Effects of histamine $\mathrm{H} 3$ receptor ligands on the rewarding, stimulant and motor-impairing effects of ethanol in DBA/2J mice. Neuropharmacology 60: 1193-1199.

39. Alachkar A, Khan N, Łażewska D, Kieć-Kononowicz K, Sadek B (2019) Histamine H3 receptor antagonist E177 attenuates amnesia induced by dizocilpine without modulation of anxiety-like behaviors in rats. Neuropsychiatr Dis Treat 15: $531-542$.

40. Benetti F, Izquierdo I (2013) Histamine infused into basolateral amygdala enhances memory consolidation of inhibitory avoidance. Int J Neuropsychopharmacol 16: 15391545. 